war sie Landesbeamtin im Sächsischen Staatsministerium für Wirtschaft, Arbeit und Verkehr mit weiteren Tätigkeiten auf Kommunalebene in der Wirtschaftsförderung, im Sachsenbüro in Brüssel und in der Bundesratskoordinierung. Seit 1990 ist sie Mitglied im djb, von 1993 bis 1995 und von 2001 bis 2003 war sie Bundesvorstandsmitglied. Sie war im Vorstand der Regionalgruppe Dresden (1993-2005) und im Vorstand des Landesverbands Sachsen (1994-2005). Katharina Wolf ist Mitglied der djb-Kommission „Öffentliches Recht, Europaund Völkerrecht“. Sie ist Gründungsmitglied der European Women Lawyers‘ Association (EWLA).

\title{
Sommerempfang des Landesverbands Berlin
}

\section{am 10. Juni 2010 in der Landesvertretung Thüringen, Berlin}

Zum traditionellen Sommerempfang des djb-Landesverbands Berlin fanden sich am 10. Juni 2010 rund 250 djb-Mitglieder und illustre Gäste aus Politik und Gesellschaft in der Thüringer Landesvertretung ein. Die diesjährige Festrednerin Marion Walsmann, Finanzministerin und ehemalige Justizministerin des Freistaats Thüringen, berichtete über Erreichtes und bestehende Herausforderungen der Gleichstellungspolitik in Thüringen und gab einen Ausblick auf den Entwurf des neuen Gleichstellungsgesetzes ihres Landes.

Mit hinreichend Gesprächs- und Diskussionsstoff versorgt, gab es im Anschluss bei Thüringer Rostbratwürstchen vom Grill und einem Buffet mit weiteren thüringer Spezialitäten auf der Dachterrasse der Landesvertretung Thüringen hinreichend Gelegenheit, sich auszutauschen und dem Knüpfen von Netzwerken zu widmen. Bei herrlichstem Sommerwetter und einer RundumAussicht auf Berlin fiel es dabei besonders leicht, auch über den Tellerrand der thüringischen Gleichstellungspolitik hinauszublicken und so einen gelungenen Abend bis nach Sonnenuntergang ausklingen zu lassen. (DB)

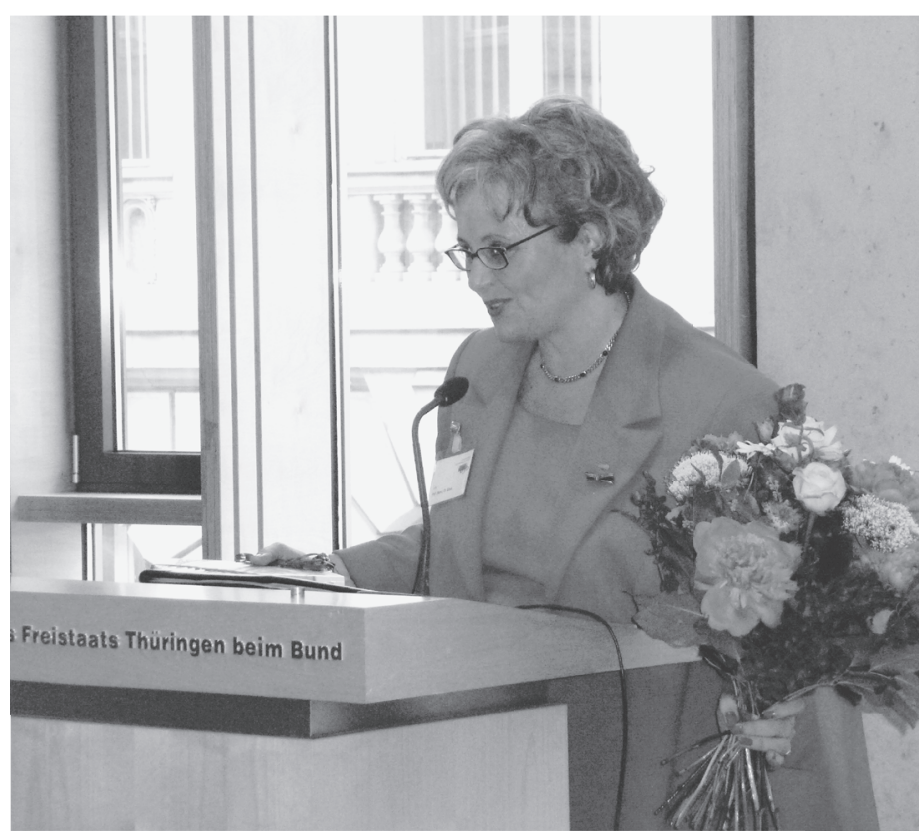

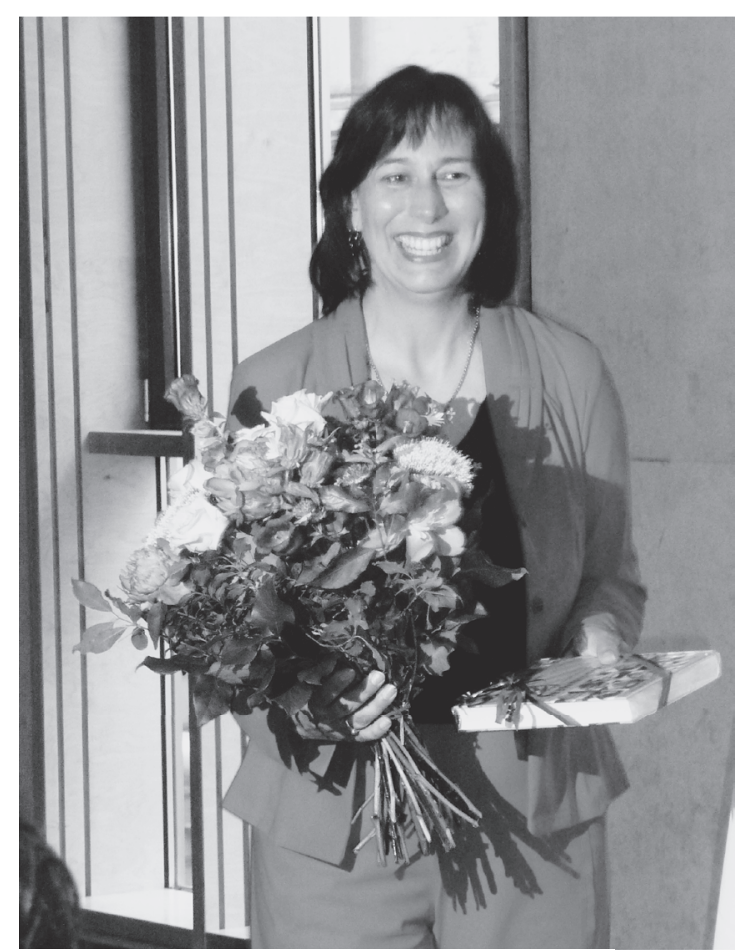

A Marion Walsmann, seit 2004 Mitglied des Thüringer Landtags und bis zur Ernennung als Thüringer Justizministerin im Mai 2008 justizpolitische Sprecherin der CDU-Landtagsfraktion, seit November 2009 Thüringer Finanzministerin. $\checkmark$ Prof. (asoc.) Dr. Jutta Glock begrüßt die Gäste des Landesverbands Berlin zum traditionellen Sommerempfang, dieses Jahr in der Vertretung des Freistaats Thüringen beim Bund. 